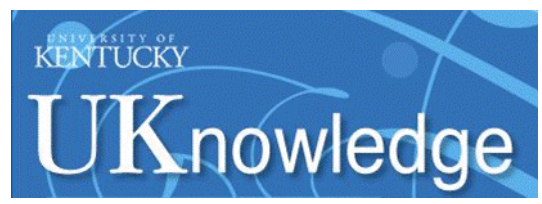

University of Kentucky

UKnowledge

$11-11-2016$

\title{
Dreams, Aspirations and Related Behavior in Children and Adolescents: Impacts on Child Developmental Outcomes
}

Florence K. Y. Wu

The Hong Kong Polytechnic University, China

Daniel T. L. Shek

University of Kentucky

Hildie Leung

The Hong Kong Polytechnic University, China

Follow this and additional works at: https://uknowledge.uky.edu/pediatrics_facpub

Part of the Child Psychology Commons, and the Developmental Psychology Commons

Right click to open a feedback form in a new tab to let us know how this document benefits you.

\section{Repository Citation}

Wu, Florence K. Y.; Shek, Daniel T. L.; and Leung, Hildie, "Dreams, Aspirations and Related Behavior in Children and Adolescents: Impacts on Child Developmental Outcomes" (2016). Pediatrics Faculty Publications. 275.

https://uknowledge.uky.edu/pediatrics_facpub/275

This Article is brought to you for free and open access by the Pediatrics at UKnowledge. It has been accepted for inclusion in Pediatrics Faculty Publications by an authorized administrator of UKnowledge. For more information, please contact UKnowledge@lsv.uky.edu. 


\section{Dreams, Aspirations and Related Behavior in Children and Adolescents: Impacts on Child Developmental Outcomes}

\section{Digital Object Identifier (DOI)}

https://doi.org/10.1515/ijdhd-2017-7002

\section{Notes/Citation Information}

Published in International Journal on Disability and Human Development, v. 16, issue 4, p. 339-349.

(C2017 Walter de Gruyter GmbH, Berlin/Boston.

The copyright holder has granted the permission for posting the article here. 


\section{Florence K.Y. Wu*, Daniel T.L. Shek and Hildie Leung}

\section{Dreams, aspirations and related behavior in children and adolescents: impacts on child developmental outcomes}

DOI 10.1515/ijdhd-2017-7002

Received August 2, 2016; accepted September 5, 2016; previously published online November 22, 2016

\begin{abstract}
Dreams", "aspirations" and related constructs are traditionally regarded as facilitators of adolescent educational attainment in the Chinese context. Besides, there is an emergent need to widen the understanding of such constructs and their impact on children and adolescent developmental outcomes. This paper discusses the developmental outcomes of dreams, aspiration and related concepts based on a thorough review of the literature. Besides outlining the impacts of aspirations, dreams and related constructs on children and adolescents, features of related intervention programs, including themes of the intervention programs, program participants, methods of implementation and evaluation in both Western and Chinese contexts are also documented.
\end{abstract}

Keywords: adolescents; aspirations; children; developmental outcomes; dreams; intervention.

\section{Introduction}

In both Western and Chinese contexts, education has been increasingly perceived as the "vehicle for meritocracy and social mobility" [1]. Nurturing children and adolescents with high educational attainment becomes the "mission" of education at all levels. However, numerous scholars

\footnotetext{
*Corresponding author: Florence K.Y. Wu, Department of Applied Social Sciences, Faculty of Health and Social Sciences, The Hong Kong Polytechnic University, Hunghom, Hong Kong, P.R. China, E-mail: florence.wu@polyu.edu.hk

Daniel T.L. Shek: Department of Applied Social Sciences, The Hong Kong Polytechnic University, Hong Kong, P.R. China; Centre for Innovative Programmes for Adolescents and Families, The Hong Kong Polytechnic University, Hong Kong, P.R. China; Department of Social Work, East China Normal University, Shanghai, P.R. China; Kiang Wu Nursing College of Macau, Macau, P.R. China; and Division of Adolescent Medicine, Kentucky Children's Hospital, University of Kentucky College of Medicine, Lexington, Kentucky, USA Hildie Leung: Department of Applied Social Sciences, The Hong Kong Polytechnic University, Hong Kong, P.R. China
}

cautioned that the increasing focus on educational attainment hinders children and adolescents to aspire for their own genuine pursuit of future and adversely affects their physical and psychological health [2-4]. Hence, it is of equal importance to encourage children and adolescents to boldly dream about their future in addition to educational attainment. Truitt et al. [5] encouraged adolescents to "dream high" so that high-hope children and adolescents would perceive obstacles to goals as "temporary" and the high level of goal-directed motivation allows them to search for "the best alternative way". It is therefore fundamental to arouse the awareness of educators, parents and human service providers of the consequences of dreams and aspirations in children and how they can assist them to "aim for something higher" [1].

As mentioned in another paper in this special issue, a collaborative research named "iDream" was conducted (a) to understand the scientific underpinnings of instilling dreams, aspirations, hope, future orientation and related qualities in children and adolescents, (b) to investigate the positive impact of such constructs on children's and adolescents' well-being and overall development and (c) to review existing interventions based on the related constructs with the financial support of the Bao Bao Bear Care Foundation Limited. The Bao Bao Bear Care Foundation Limited was founded in 2008 subsequent to the Sichuan earthquake to facilitate the provision of programs to children in Sichuan, China. The vision of the organization is that in spite of adverse experiences, children should not be deprived of the opportunity to experience a sense of hope. The iDream initiative was thus established to inspire and encourage children to explore their dreams and to promote their future orientation. It is believed that by exposing children to the success stories of various professionals, children would be able to understand the life trajectory leading to success and generate hope for their own future.

The present paper is one of the three papers based on the final report of the collaborative research [6]. This paper focuses on three aspects of the study: (a) methodology of the literature review, (b) consequences of having dreams and aspirations and (c) existing interventions on the promotion of dreams, aspirations and related psychology in children and adolescents. 


\section{Methods}

Conducting literature review is a process of "re-viewing" the existing literature to create a new dimension or fresh perspective to sharpen the conceptual understanding [7]. Hart [8] reminded researchers that the need to thoroughly understand the body of knowledge is crucial before administering any research. According to Pawson and his colleagues [9], there are seven steps for a systematic review, namely (1) clarify the scope of review; (2) search for relevant evidence; (3) appraise quality of studies using judgment to supplement formal checklists; (4) extract different data from different studies; (5) synthesize data to achieve refinement of the literature; (6) make recommendations and (7) disseminate findings and evaluate the extent to which the findings are able to benefit the field.

In the present literature review, the scope is about the dreams, aspirations and related development in children and adolescents. Besides, the features of effective intervention programs in these areas in the context of China would be described. The peer-reviewed literature search methodology was adopted to review the literature related to hope and dreams of children and adolescents, and a quasi-realist approach [9] was utilized to synthesize the data with reference to (a) conceptual review of the concepts covered in the present literature review, (b) antecedents affecting the development of hope and aspirations of children and adolescents and (c) possible outcomes of having developed the attributes. According to Pawson et al. [9], the quasi-realist approach has been frequently utilized to generate reliable and usable findings for describing how complex interventions function in different contexts. This approach does not over-rely upon the review of "what works" but yields the understanding of what works "for whom, under what circumstances, in what respects and how" [9]. This requires moving beyond typical study design assessment criteria such as statistical power and sampling design. The focus lies on the descriptive details about the intervention process and context instead. The "quasi-" approach helps to look into the different population orientations and multi-level components that would help substantiate the understanding of what effective and appropriate programs could be implemented in China.

\section{Peer-reviewed literature search methodology}

To identify relevant literature for the review, a detailed search of the literature published during the period of 1980 and 2015 was conducted from February to June 2015, with the use of the online databases, including PsycINFO, Academic Search Premier, Web of Science, EBSCOhost database and China's database CAJ Full-text Database. CAJ Full-text Database was adopted for searching for articles published in China. The single keywords "dreams", "hope", "aspirations", "future orientation", "resilience", "beliefs in the future", "children”, "adolescents" and the combinations of keywords with Boolean operators (and/or/*) were utilized as the search (e.g. "dreams AND hope AND children"; "aspirations AND future orientation”; "hope” OR "aspirations”; "child^ AND adolescents ${ }^{\star}$ ”; "China OR Chinese OR Hong Kong*”). Articles were included if they met the following four selection criteria: (1) the focus is on youth population which was defined a priori as individuals aged between 6 and 18 years; (2) the study or program addressed the conceptualization of dream or related concepts; (3) the study or program covered the development or validation of measurement tools of dreams or its related concepts and (4) the study or program was conducted or developed either in the Chinese or in the Western context.

The initial focus of the review was on Western- and China-based research, with special focus on the context of China. All articles in English and Chinese were included, as were articles in other languages in which an English or Chinese abstract was available. The titles of all publications were identified with possible relevance. The abstracts were reviewed if they appeared to meet the selection criteria. The full publication would then be obtained and a decision was made whether the article should be included or not. There were altogether 223 articles, with 144 being found in the international databases and 79 in China's database.

In order to produce reliable and comparable findings from the existing literature and to decide if the knowledge obtained could be translated into new directions and interventions, there is an immense need to adopt a systematic approach to "appraise, interpret and synthesize literature from divert sources” [10]. The systematic approach requires a set of clear arguments to review and synthesize the literature. Therefore, the quasi-realist approach was adopted to gauge the understanding of "what really works" for children and adolescents in developing hope and aspirations and of other knowledge beyond this understanding.

\section{Consequences of dreams, aspira- tions and related development}

The present literature review suggests that dream and its related constructs such as resilience, hope, aspirations, future orientation and belief in the future are positively associated with children and adolescent outcomes across different domains, including the psychological, academic, vocational and behavioral domains.

\section{Psychological outcomes}

The positive impact of resilience, hope and aspirations on children's and adolescents' psychological well-being is well documented in the Western literature. More hopeful adolescents reported higher levels of life satisfaction [4, 11-14] and lower levels of psychological distress [11]. Hope also acted as a buffer against the impact of negative or stressful life events on life satisfaction [4]. Similarly, adolescents with more positive beliefs in the future possessed higher self-esteem and self-efficacy [15]. More resilient youth also perceived lower levels of stress and were more satisfied with life [16].

The majority of the studies conducted in China focused on examining the impact of resilience and aspirations on psychological well-being of children and adolescents, especially those who experienced negative life events (e.g. survivors of earthquakes, children of parents 
with HIV). Findings are consistent with the Western literature that resilient youth experienced higher levels of life satisfaction [17] and were less likely to demonstrate obsessive-compulsive [18], depressive [19, 20] and posttraumatic stress disorder symptoms [21]. Future orientation also predicted Chinese adolescents' levels of anxiety, depression [22] and subjective well-being. The positive impact of resilience, hope and future orientation on individual's psychological well-being may be explained by several factors: (1) resilient children and adolescents often experience higher levels of positive emotions than their less resilient counterparts, even in times of difficulties; (2) they are able to use cognitive coping strategies such as finding opportunities for growth from challenges; (3) it is believed that they have the ability to control their environment and (4) they set realistic goals which may help them reduce difficulties in life [16].

Lastly, Gan et al. [23] found that positive future expectations were significantly correlated with resilience among adolescents who experienced the Sichuan earthquake. Indeed, the findings point toward the fact that less resilient adolescents may have difficulty in envisioning or thinking positively about their future and that "a person's future is not merely the result of his or her life circumstances; the future is also predicted by the manner in which a person thinks about it" [23]. The findings have important implications for the integration of both resilience and future expectation components in interventions.

\section{Academic outcomes}

Evidence from studies in the West generally showed that adolescents with higher levels of future orientation had higher academic achievement [24]. They attached significantly higher value to achievement of academic goals and perceived studying hard as instrumental in achieving goals [25]. Similarly, more hopeful youth tend to have higher academic achievement [12, 26, 27] as well. Many studies on the impact of students' aspirations on academic achievement showed similar observations, where students with higher levels of aspirations showed higher levels of grade point averages [28, 29] and increased school engagement across domains including behavioral, emotional and cognitive engagement [29]. In a longitudinal study of the impact of adolescent future orientation on adult educational attainment, Beal and Crockett [30] also found that adolescent aspirations positively predicted adult educational attainment 8 years later. Similarly, future orientation increased students' likelihood of staying in school [31] and attending college [32].
Similar findings were observed in studies conducted in China. Zhao and colleagues [33] examined correlates of problem behaviors among children affected by HIV and found that low educational aspirations had direct negative effects on school adjustment. Children's early expectations were strong predictors of children's chances of staying in school, completing compulsory education and completing secondary education as well [34]. Zhang [34] found that future orientation had positive influences on junior secondary school students' learning attitude, academic help-seeking behavior and academic achievement. Chen [35] also found that university students who were more future-oriented were more engaged in their studies. Higher levels of resilience were also associated with better educational outcomes of migrant children, including more effort put into study, higher educational aspirations and less intention to drop out of school [36].

The positive associations between aspirationrelated variables and academic outcomes may be due to several factors. First, adolescents with high aspirations develop goals for the future, which serves as a motivation for higher academic achievement. Second, highhope students are more willing to find solutions when they encounter difficulties and try new approaches. On the other hand, low-hope students are often more passive and seldom learn from past experiences, which may hinder academic achievement. As pointed out by Snyder et al. [27], "teaching hopeful thinking has the potential to improve the students' goal pursuits in all areas of their lives, thereby leading to more positive emotions, greater psychological adjustment and more social support” [27].

\section{Vocational outcomes}

In terms of career-related outcomes, studies from the West generally showed that adolescents with higher levels of aspirations had higher levels of future career accomplishments and achievement [37-42]. For instance, in a longitudinal study in the United Kingdom, Schoon and Polek [43] found that career aspirations measured at the age of 16 years positively predicted career attainment in their mid-30s, even after controlling family background and cognitive ability. Specifically, teens who aspired to a professional job were more likely to pursue further education and were more likely to achieve their occupational aspirations as adults. Few studies were directly related to the variables of interest in the context of China, with some exceptions of scholars examining the impact of 
occupational expectations on vocational outcomes. It was reasoned that more hopeful and highly aspired youth may be more persistent and ambitious to achieve their career goals [43]. For instance, Huang and Bashir [44] found that occupational expectations positively predicted occupational self-efficacy.

Strauss, Griffin and Parker [45] identified a positive impact of "Future work self" on proactive career behavior. Although the study was conducted on postgraduate students, the findings yielded practical implications for youth hope-based interventions. A "Future work self" refers to "an individual's representation of himself or herself in the future that reflects his or her hopes and aspirations in relation to work. The clearer and more accessible this representation is, the more salient the Future work self is" [45]. Individuals with a salient Future work self (i.e. they have a clear image of themselves in a future career) are more willing to take risks and set ambitious goals. They would broaden their creative thinking about future possibilities which motivate them to proactively shape their careers. These findings highlight the importance of cultivating elaborative Future work selves through career counseling. Role models may be used to help construct ideals and possible Future work selves. Cognitive strategies may also be taught to help students envision their Future work self.

\section{Behavioral outcomes}

Studies in both the Western and Chinese contexts showed that aspirations and related constructs serve as protective factors against the development of problem behaviors in children and adolescents. According to Robbins and Bryan [46], adolescents with stronger future orientation were more likely to perceive risk behaviors negatively. They were less likely to smoke cigarettes, use marijuana or hard drugs or engage in problematic drinking [46-51]. Regarding hope, Hagen and colleagues [52] found that more hopeful adolescents reported fewer internalizing and externalizing problems. In a longitudinal study of high-school students, Ciarrochi and colleagues [26] reported that lower levels of hope predicted higher rates of behavioral problems (e.g. aggression and inattention). Hope was also related to lower levels of involvement in violence [53]. Regarding the impact of aspiration on adolescent problem behaviors, most studies reported a negative relationship. Generally speaking, youth with high aspirations are less likely to drink alcohol or get drunk [54-57]. They also reported lower levels of cigarette [54] and substance use [58], risky sexual behavior [59] and premarital child-bearing [60-64].

Compared to the West, few studies have been conducted to examine the impact of aspiration-related factors on problem behaviors among children and adolescents in China. Among the sparse articles identified, findings comparable to those reported in the West were found. For instance, Zhao and colleagues [33] found that low levels of educational aspiration were negatively associated with problem behaviors among orphans and vulnerable children affected by parental HIV. Li et al. [65] also found that middle-school male students with lower educational expectations reported more cigarette smoking. Du et al. [66] conducted a study on rural-to-urban migrant children and found that individualistic orientation predicted higher levels of hopelessness and subsequently more substance-use behavior. The authors reasoned that China is a collectivistic culture and thus collectivistic orientation (as opposed to individualism) and coping such as family support play important protective roles in developing hope and against engagement in problem behavior.

Besides problem behavior, some studies showed that aspiration-related constructs were correlated with healthy behaviors. For instance, youth who had a more positive belief about their ability to live a healthy lifestyle had better attitudes and skills in living a healthy lifestyle (e.g. exercising and eating healthily) [67]. Students having high aspirations were also more responsible for their health and reported higher levels of nutrition and exercise [68]. These findings underscore the important role of cognitive beliefs on attitudes and choices in lifestyle and health-promoting behaviors. In terms of prosocial behaviors, Syvertsen et al. [69] found that rates of community service for youth with college aspirations increased considerably more than the rates of community service for those with other post-high school plans. Wang et al. [68] argued that adolescents who have higher levels of aspirations would be more likely to be prosocially involved in the community.

Taken as a whole, findings in both the Western and Chinese contexts showed the positive impact of hope, resilience, future orientation, beliefs in the future and aspirations on different domains of children and adolescents' life, including the psychological, academic, vocational and behavioral domains. Findings highlight the importance of developing interventions that target both skill-building and efficacy-enhancing elements to help children and adolescents better understand their cognitive-affective responses to adversities, and providing them with the ability to take advantage of life opportunities to maintain a hopeful outlook on life. 


\section{Existing interventions}

The literature review showed that there are many intervention programs implemented in the Western context to help children and adolescents to search for their dreams, hope and aspirations. Indeed, hope-based interventions that help students to explore their goals and identify actions to achieve have been shown to promote life satisfaction in students [12]. In contrast, there are very limited intervention programs facilitating children and the youth to explore their dreams, aspirations and hopes in different Chinese contexts. In the past three decades, there were less than ten published intervention programs addressing aspiration and related constructs in China. Themes like exploring hope, future orientation or dreams for children and adolescents were scarcely found in the literature. As such, there is much capacity to develop intervention programs with these themes to help children and adolescents to understand themselves and capacities to realize their potential in mainland China.

\section{Themes/foci of the intervention programs}

The coverage of themes of the intervention programs implemented in the Western context is wide. For example, there are programs encouraging low-income youth or juvenile delinquents to explore the meaning of hope to them and what future orientation could be focused on if they wish to step out from their present situation $[70,71]$. There are also programs helping children of divorced families or adolescents with depression to strengthen their decision-making ability and thus developing their sense of self-efficacy and resilience [72-74]. The intervention programs were designed for targeted children and youth, and the contents were context- and target-group-specific. However, there are very few programs helping children or youth to explore their needs and aspirations.

Among the limited intervention programs in the Chinese context, "aspiration" is the major theme, with special attention to explore and develop "academic aspiration" of children and adolescents [75]. There is a strong conviction that children's future is constituted by academic excellence in traditional Chinese context. Nurturing academic aspiration became the prime concern of the intervention programs in China and there are very few intervention programs exploring hope, aspiration or other aspects of future orientation. One interesting finding in the Western literature is that some of the program designers held quite strong beliefs about youth's educational or academic development, which aligned with the Chinese context, to help them understand what hope and aspiration mean to them $[71,76]$. They believed that creating successful academic experiences may help the youth to aspire to achieve ambitious goals later in life. However, the meaning of "success" or "aspiration" could be varied from the youth's perspective with different cultural backgrounds. As such, there is an immense need to develop programs to help children and adolescents widen their exploration of their future hope or aspirations with their internal frame of reference in the Chinese context.

In Hong Kong, a successful positive youth development program entitled Project P.A.T.H.S. (denoting Positive Adolescent Training through Holistic Social Programs) was developed and implemented for young adolescents in secondary schools [77-79]. The program was intended to promote students' holistic development by enhancing their intrapersonal and interpersonal competencies. With particular relevance to the present review, the P.A.T.H.S. curriculum includes sessions aiming at promoting students' resilience, beliefs in the future and spirituality for Secondary 1-3 students. Indeed, most existing dream- and aspiration-based interventions in Chinese contexts focus on nurturing students' academic aspirations, which is merely one aspect of aspirations. However, the present review revealed that dreams and aspirations are far more encompassing. Therefore, it is important to encourage youngsters to discover their unique strengths and potential beyond merely academic achievements to reflect on and understand what interests them and what their meaning in life is. Moreover, it is important to equip adolescents with competencies such as resilience and help them adopt a positive outlook on life so that they are able to overcome adversities and challenges as they strive to achieve their dreams.

\section{Program participants}

Quite a number of intervention programs implemented in the Western contexts were designed for youth with special needs, such as low-income youth [71, 80], juvenile delinquents [70], AIDS-orphaned youth [81], children from single-parent families [76, 82] or children and adolescents with emotional and behavioral problems [83]. The number of children and adolescents served in these programs varied from a few dozen youth $[50,70]$ to a few hundred children and adolescents from various schools $[73,84]$. Most of these programs had positive effects on the future orientation of the adolescents and they assisted 
young people to develop higher levels of continuity, hope and career decidedness. However, the above-mentioned programs catered for a specific target group of children and adolescents and there are limited programs helping youth in the general population to explore their dreams, aspirations or future orientation. Pittman and Irby [85] stated that "problem-free is not fully prepared". Hence, it is recommended to advocate programs catering for all the children and adolescents to allow them to experience the "exploration" and "creation" of their own dreams and aspirations.

In the context of China, the programs implemented have made an attempt to cater for youth in the general population without much restriction in the recruitment. However, the number of children and adolescents served was limited to a few dozen, and the served participants were from well-off cities, such as Beijing and Shanghai [75]. There were few programs implemented to serve the children and adolescents in other provinces, especially the more rural villages or the remote western part of China. Lai [86] stated that the remote western region of China should actively prepare for the future development to reduce regional inequality that might hinder the future development of the children and adolescents in those areas. There is a need to extend the implementation of the interventions to these regions or provinces so that children and adolescents in these regions are able to be exposed to the development of the well-off regions. Most importantly, the future development of their regions will allow them to explore their own meanings of dreams, aspirations and future orientation with a better understanding of the strengths and limitations of their own living environments.

With reference to the CEDAR (Career Exploration, Development and Resources group) program, the Chinese youth who newly immigrated to the USA struggled with language barriers, cultural adjustment and academic demands and many of them expressed "uncertainty about their future" [87]. The "uncertainty" is applicable to the mainland Chinese adolescents as well. Young people might have followed their families to move to different provinces as migrant children or adolescents. The migrant adolescents found it difficult to adapt to school or other social settings. When programs are designed for the mainland children and adolescents to explore their future aspirations or dreams, these difficulties should be taken into account and acknowledged. Hence, a trustworthy and open atmosphere could be cultivated in the programs in which the adolescents could share their values and discuss challenges they would perceive as barriers in the environment.

\section{Methods of implementation}

In the Western contexts, the intervention approach varied from intensive arranged activities, such as summer camps [84] or intensive classes arranged every school day for 3 months [70], to class-based or curriculum-based lessons held regularly with interactive activities $[50,88,89]$. For the intensive programs, the participants reported significant changes of having more ability to initiate and sustain movement toward their goals and having the ability to create positive future for themselves right after participating in the programs. However, the researchers expressed their concern over the sustainability of these changes on children and adolescents as there were few longitudinal follow-up studies to show long-lasting effects on the participants [84].

For the class-based or curriculum-based intervention programs, the participants reported positive effects on developing goals and aspirations and having higher levels of hope and optimism. There are positive long-term effects on the participants in these programs as the participants were given sufficient time to incorporate the training and learning in the programs with their life experiences [71, 81]. The regularly held classes (either incorporated into school curriculum or arranged as after-school programs) provided a steady time-frame to the youth participants to learn regularly and gradually, creating a stable socialfriendly environment to the participants to establish social connection with other participants.

Some intervention programs carried out in the Western contexts were individual-based such as individual psychotherapy session [90] or in-home sessions [74]. The participants served in these programs were quite limited (8-15 participants). Besides, the small-scale designs did not instill significant positive changes in the participants in understanding hope and generating aspirations [74].

In the context of China, mere lecturing and collective instructions are the most common approaches in helping children and adolescents to understand what "aspirations", "dreams" or "future orientation" means in these programs [91, 92]. The teachers or facilitators of the programs taught what "aspirations" or "future goals" were and students learnt the concepts in a more directive and guided manner. There is rare opportunity for children and adolescents to explore the meanings of "aspirations", "hopes" or "dreams" to themselves in class. Even though some implementers arranged outdoor activities such as visits to museums of traditional Chinese heroes [75], interactive classroom activities (including group discussions, role-plays or card games) or engaging teaching approaches (including self-disclosure of teachers and 
students or collaborative learning) were seldom carried out in these programs. Interactive classroom activities and engaging teaching approaches were found effective in assisting adolescents to look inwardly upon their genuine needs and producing better implementation quality in the Chinese context [93]. Some programs have adopted the group counseling approach to assist the Chinese immigrant youth in the USA to explore their career interests, skills, abilities, priorities and different career options [94]. The group counseling approach is able to provide a "safe haven" for the Chinese youth participants to share their concerns and aspirations in a trustworthy milieu and the collaboration. The communication among the participants helps weave the friendship web that provides socioemotional support and great resources to the participants. Incorporating these approaches into the intervention programs in the context of China might help facilitate the children and adolescents to search for their own meanings of aspirations, hopes and dreams instead of being taught by the teachers or implementers.

Practical information such as college applications or resume writing has also been provided in some of the programs and the information provided has helped the participants foster a sense of competence in career exploration $[87,94]$. However, the provision of hands-on information on the work lives of different professionals is rarely found in the literature, especially in the Chinese context. It is recommended to prepare more hands-on information for the participants, for example introducing the work values, ethics or prospect of different professionals, or resume writing and college applications.

Besides approaches and intervention methods, implementers in the intervention programs also varied. The implementers of intervention programs in the Western contexts are mostly professionals in human services such as educationalists, psychologists, counselors, social workers or researchers of the programs. For example, the programs helping low-income youth and aiming to reduce their hopelessness invited school personnel (teachers or guidance counselors) or a career counseling psychologist to deliver the programs $[72,73]$. In addition to these professionals in human services, other professionals such as professional dancers or artists were also invited as collaborators $[80,84]$. The professionalism of the implementers helped deliver professional knowledge to the participants and thus enriched the participants' understanding of the related concepts. The involvement of the implementers other than human service professionals exposed the participants to new leisure or career options and opportunities [70]. However, the professional image of the implementers has distanced the participants and might have hindered the engagement between the implementers and the participants. More preparation work, such as pre-program meetings with the participants or extra time offered to the participants to know the implementers in each session, has to be done when involving professional counterparts in the intervention programs.

Chung [95] observed that Asian clients have a tendency to expect directive guidance, information-driven and problem-solving approach to assist them for the personal and career exploration. That is why the Chinese participants of these intervention programs would have high expectations on the facilitators to serve multiple roles such as an adviser, a role model, an authority to provide directions and an expert with solid professional knowledge. The implementers would use different means to facilitate the participants to explore and search for their potential and aspirations in an in-depth manner by, for example, arranging the students or participants in groups, using card games, discussions and reflective exercises. Some of the implementers have utilized the imitating case scenarios for small group discussion [94]. Making use of the case scenarios was less intimidating and was more congruent with Chinese concern with "loss of face" in disclosing their thoughts, wishes, perceived "unrealistic" dreams (that might be their genuine dreams) and feelings toward achieving these dreams and wishes [96].

One of the unique features of the intervention programs in both Western and Chinese contexts is to invite guest speakers, such as alumni or professionals from different fields [70, 78, 94], to share [1] their experiences of how they chose their career pathways, [2] struggles met in the process and [3] ways to be resilient in facing obstacles. Some of the guest speakers shared similar backgrounds of the participants (e.g. the alumni) to draw closer linkages to the children or adolescent participants [70] and some of the guest speakers were the successful figures in the society to arouse participants' interests to better understand the respective field. In the 1980s, the focus of sharing was about how to set goals and their success stories [75]. The guest speakers typically acted like "role models" for the participants to demonstrate the possibilities of being competent in respective fields. The feasible "accessibility" to these significant others in the participants' socio-cultural system offers prime opportunities for the youth to explore more educational and vocational possibilities, ways to pursue their aspirations and hopes, and the basic or fundamental skills in respective workplaces [54, 94].

Some final remarks on evaluation are in order. Different methods have been used to evaluate the programs under review. A number of programs have shown the 
effectiveness in helping their participants to reduce their sense of hopelessness [72], increase adolescents' hope for the future [73, 80, 84], occupational, educational and academic aspiration [79] and enhance resilience of children and adolescents $[88,97]$. However, there are very few longitudinal evaluation studies to investigate the long-term impacts of these programs on the participants. The importance of administering longitudinal studies is shown in some pioneering positive youth development programs in the Chinese context [98]. Administering program evaluation is crucial to understand "how" and "why" the program works [99].

\section{Conclusions}

In this review, we examined the consequences of having dreams, aspirations and related attributes. Studies have shown that resilience, aspirations and future orientation serve as protective factors against problem behaviors. Students with lower levels of future orientation were more likely to engage in problem behaviors such as smoking, drinking or drug abuse. Moreover, high-school students with low levels of hope exhibited more externalizing behaviors (e.g. aggression and delinquency). In addition, positive youth development studies have also shown that resilient youth, who had a positive belief in the future and/or a higher level of spirituality (including meaning and purpose in life), reported higher levels of connectedness to the community and a sense of contribution, which serve as protective factors against the development of problem behaviors.

The present study also documented features of the intervention programs implemented in both Western and Chinese contexts. It is recommended to design and implement indigenous intervention programs that meet the needs of Chinese children and adolescents in the context of China. The specific Chinese culture has been quite often overlooked in implementing intervention programs on aspirations, hope or resilience building. Leong and Gim [100] cautioned that the submissive and passive image drawn by traditional patriarchal society might confine the range of exploration and choices of Chinese adolescents (especially female youth) when they make life-long decisions. Hence, program implementers have to be well aware of these subtle Chinese cultural concerns while they are carrying out intervention programs. In particular, it is crucial to create an open and trustworthy environment for the youth participants to process personal yet complex feelings and thoughts during the process of program implementation.
Acknowledgments: This research was financially supported by The Bao Bao Bear Care Foundation Limited. The materials in this paper are based on the unpublished report entitled "Literature Review on Hope and Aspirations in Children and Adolescents" submitted to the Foundation.

\section{References}

1. Rose J, Baird JA. Aspirations and an austerity state: young people's hopes and goals for the future. London Rev Educ 2013;11:157-73.

2. Juvakka T, Kylmä J. Hope in adolescents with cancer. Eur J Oncol Nurs 2009;13:193-9.

3. Spohrer K. Deconstructing ‘Aspiration': UK policy debates and European policy trends. Educ Res Eval 2011;10:53-63.

4. Valle MF, Huebner ES, Suldo SM. An analysis of hope as a psychological strength. J Sch Psychol 2006;44:393-406.

5. Truitt M, Biesecker B, Capone G, Bailey T, Erby L. The role of hope in adaptation to uncertainty: the experience of caregivers of children with Down syndrome. Patient Educ Couns 2012; 87:233-8.

6. Wu FK, Leung H, Shek DT. Collaborative research report on "Literature review on hope and aspirations in children and adolescents". [Unpublished manuscript] Hong Kong: Department of Applied Social Sciences, The Hong Kong Polytechnic University, 2015.

7. Jesson J, Matheson L, Lacey FM. Doing your literature review: traditional and systematic techniques. London: Sage, 2011.

8. Hart C. Doing a literature review: releasing the social science research imagination. London: Sage, 1998.

9. Pawson R, Greenhalgh T, Harvey G, Walshe K. Realist synthesis: an introduction. Manchester: ESRC Research Methods Programme, University of Manchester, 2004.

10. Khanlou N, Wray R. A whole community approach toward child and youth resilience promotion: a review of resilience literature. Int J Ment Health Addict 2014;12:64-79.

11. Gilman R, Dooley J, Florell D. Relative levels of hope and their relationship with academic and psychological indicators among adolescents. J Soc Clin Psychol 2006;25:166-78.

12. Marques SC, Pais-Ribeiro JL, Lopez SJ. The role of positive psychology constructs in predicting mental health and academic achievement in children and adolescents: a two-year longitudinal study. J Happiness Stud 2011;12:1049-62.

13. Marques SC, Lopez SJ, Mitchell J. The role of hope, spirituality and religious practice in adolescents' life satisfaction: longitudinal findings. J Happiness Stud 2013;14:251-61.

14. Vacek KR, Coyle LD, Vera EM. Stress, self-Esteem, hope, optimism, and well-being in urban, ethnic minority adolescents. J Multicult Couns Devel 2010;38:99-111.

15. Bryan A, Aiken LS, West SG. HIV/STD risk among incarcerated adolescents: optimism about the future and self-esteem as predictors of condom use self-efficacy. J Appl Soc Psychol 2004;34:912-36.

16. Abolghasemi A, Varaniyab ST. Resilience and perceived stress: predictors of life satisfaction in the students of success and failure. Procedia Soc Behav Sci 2010; 5:748-52.

17. Liu Y, Wang ZH, Li ZG. Affective mediators of the influence of neuroticism and resilience on life satisfaction. Pers Individ Dif 2012;52:833-8. 
18. Sun J, Li ZJ, Buys NJ, Storch EA, Wang JS. Obsessive-compulsive symptoms and personal disposition, family coherence and school environment in Chinese adolescents: a resilience approach. J Affect Disord 2014; 168:459-65.

19. Wang B, Li X, Barnett D, Zhao G, Zhao J, Stanton B. Risk and protective factors for depression symptoms among children affected by HIV/AIDS in rural China: a structural equation modeling analysis. Soc Sci Med 2012;74:1435-43.

20. Ye Y, Fan F, Li L, Han Q. Trajectory and predictors of depressive symptoms among adolescent survivors following the Wenchuan earthquake in China: a cohort study. Soc Psychiatry Psychiatr Epidemiol 2014;49:943-52.

21. Ying L, Wu X, Lin C, Jiang L. Traumatic severity and trait resilience as predictors of posttraumatic stress disorder and depressive symptoms among adolescent survivors of the Wenchuan earthquake. PLoS One 2014;9:e89401.

22. Yu XN, Lau JT, Mak WW, Zhang J, Lui WW. Factor structure and psychometric properties of the Connor-Davidson Resilience Scale among Chinese adolescents. Compr Psychiatry 2011;52:218-24.

23. Gan Y, Xie X, Wang T, Rodriguez MA, Tang CS. Thriving in the shadow of the 2008 Sichuan earthquake: two studies on resilience in adolescents. J Health Psychol 2013;18:1232-41.

24. Mello ZR, Worrell FC. The relationship of time perspective to age, gender, and academic achievement among academically talented adolescents. J Educ Gifted 2006;29:271-89.

25. De Volder ML, Lens W. Academic achievement and future time perspective as a cognitive-motivational concept. J Pers Soc Psychol 1982;42:566-71.

26. Ciarrochi J, Heaven PC, Davies F. The impact of hope, selfesteem, and attributional style on adolescents' school grades and emotional well-being: a longitudinal study. J Res Pers 2007;41:1161-78.

27. Snyder CR, Shorey HS, Cheavens J, Pulvers KM, Adams III VH, Wiklund C. Hope and academic success in college. J Educ Psychol 2002;94:820-6.

28. Akos P, Lambie G, Milsom A, Gilbert K. Early adolescents' aspirations and academic tracking: an exploratory investigation. Sch Couns 2007;11:57-64.

29. Hill NE, Wang MT. From middle school to college: Developing aspirations, promoting engagement, and indirect pathways from parenting to post high school enrollment. Dev Psychol 2015;51:224-35.

30. Beal SJ, Crockett LJ. Adolescents' occupational and educational aspirations and expectations: links to high school activities and adult educational attainment. Dev Psychol 2010;46:258-65.

31. Marjoribanks K. Family contexts, individual characteristics, proximal settings, and adolescents' aspirations. Psychol Rep 2002;91:769-79.

32. South SJ, Baumer EP, Lutz A. Interpreting community effects on youth educational attainment. Youth Soc 2003;35:3-36.

33. Zhao Q, Li X, Gu C, Zhao J, Zhao G. Correlates and mediators of problem behaviors among children affected by HIV/AIDS in rural China: a structural equation modeling analysis. J Child Fam Stud 2015;24:2892-904.

34. Zhang Y. The hopes carry them on: Early educational expectations and later educational outcomes in rural Gansu China. In Family Environments, School Resources, and Educational Outcomes (Research in the Sociology of Education, Vol. 19). Emerald Group Publishing Limited, 2016:149-85.
35. Chen Y. The relationship of university students' future orientation, specialty identity and study engagement. Sichuan U Arts Sci J 2013;23:91-5.

36. Wu Q, Tsang B, Ming H. Social capital, family support, resilience and educational outcomes of Chinese migrant children. Br J Soc Work 2014;44:636-56.

37. Cochran DB, Wang EW, Stevenson SJ, Johnson LE, Crews C. Adolescent occupational aspirations: test of Gottfredson's theory of circumscription and compromise. Career Dev Q 2011;59:412-27.

38. Croll P. Occupational choice, socio-economic status and educational attainment: a study of the occupational choices and destinations of young people in the British Household Panel Survey. Res Papers in Educ 2008;23:243-68.

39. Marjoribanks K. Family learning environments and students' outcomes: a review. J Comp Fam Stud 1996:373-94.

40. Schoon I, Martin P, Ross A. Career transitions in times of social change. His and her story. J Vocat Behav 2007;70:78-96.

41. Schoon I, Parsons S. Teenage aspirations for future careers and occupational outcomes. J Vocat Behav 2002;60:262-88.

42. Yates S, Harris A, Sabates R, Staff J. Early occupational aspirations and fractured transitions: a study of entry into 'NEET'status in the UK. J Soc Policy 2011;40:513-34.

43. Schoon I, Polek E. Teenage career aspirations and adult career attainment: the role of gender, social background and general cognitive ability. Int J Behav Dev 2011;35:210-7.

44. Huang HY, Bashir M. Examining the gender gap in information assurance: a study of psychological factors. In $\mathrm{HCl}$ International 2015-Posters' Extended Abstracts. Springer International Publishing, 2015:117-22.

45. Strauss K, Griffin MA, Parker SK. Future work selves: how salient hoped-for identities motivate proactive career behaviors. J Appl Psychol 2012;97:580-98.

46. Robbins RN, Bryan A. Relationships between future orientation, impulsive sensation seeking, and risk behavior among adjudicated adolescents. J Adolesc Res 2004;19:428-45.

47. Adams J. Consideration of immediate and future consequences, smoking status, and body mass index. Health Psychol 2012;31:260.

48. Barnett E, Spruijt-Metz D, Unger JB, Rohrbach LA, Sun P, Sussman $\mathrm{S}$. Bidirectional associations between future time perspective and substance use among continuation high-school students. Subst Use Misuse 2013;48:574-80.

49. Chen P, Vazsonyi AT. Future orientation, school contexts, and problem behaviors: a multilevel study. J Youth Adolesc 2013;42:67-81.

50. McCay BJ, Jones PJ. Marine protected areas and the governance of marine ecosystems and fisheries. Conserv Biol 2011;25:1130-3.

51. Peters RJ, Tortolero SR, Johnson RJ, Addy RC, Markham CM, Escobar-Chaves SL, et al. The relationship between future orientation and street substance use among Texas alternative school students. Am J Addict 2005;14:478-85.

52. Hagen KA, Myers BJ, Mackintosh VH. Hope, social support, and behavioral problems in at-risk children. Am J Orthopsychiatry 2005;75:211-9.

53. Stoddard SA, McMorris BJ, Sieving RE. Do social connections and hope matter in predicting early adolescent violence? Am J Community Psychol 2011;48[3, 4]:247-56.

54. Cook WK, Hofstetter CR, Kang M, Hovell MF, Irvin V. Rethinking acculturation: a study of alcohol use of Korean American ado- 
lescents in Southern California. Contemp Drug Probl 2009;36[1, 2]:217.

55. Crum RM, Storr CL, Anthony JC. Are educational aspirations associated with the risk of alcohol use and alcohol userelated problems among adolescents? Subst Use Misuse 2005;40:151-69.

56. Dunn MS, Kitts C, Lewis S, Goodrow B, Scherzer GD. Effects of youth assets on adolescent alcohol, tobacco, marijuana use, and sexual behavior. J Alcohol Drug Educ 2011;55:23-40.

57. Liu XC, Keyes KM, Li G. Work stress and alcohol consumption among adolescents: Moderation by family and peer influences. BMC Public Health 2014;14:1303.

58. Henry KL. Who's skipping school: characteristics of truants in 8th and 10th grade. J Sch Health 2007;77:29-35.

59. Kalina O, Geckova AM, Klein D, Jarcuska P, Orosova O, van Dijk JP, et al. Psychosocial factors associated with sexual behaviour in early adolescence. Eur J Contracept Reprod Health Care 2011;16:298-306.

60. Davis TM. An examination of repeat pregnancies using problem behavior theory: Is it really problematic? J Youth Stud 2002;5:337-51.

61. East PL. Racial and ethnic differences in girls' sexual, marital, and birth expectations. J Marriage Fam 1998;60:150-62.

62. O'Connor ML. Academically oriented teenage women have reduced pregnancy risk. Perspect Sex Reprod Health 1999;31:105-6.

63. Plotnick RD. The effects of attitudes on teenage premarital pregnancy and its resolution. Am Sociol Rev 1992;57:800-11.

64. Witwer M. Pregnancy risk lessened for teenagers with high educational aspirations. Perspect Sex Reprod Health 1993;25:189.

65. Li X, Fang X, Stanton B. Cigarette smoking among schoolboys in Beijing, China. J Adolesc 1999;22:621-5.

66. Du H, Li X, Lin D, Tam CC. Hopelessness, individualism, collectivism, and substance use among young rural-to-urban migrants in China. Health Psychol Behav Med 2014;2:211-20.

67. Kelly SA, Melnyk BM, Jacobson DL, O'Haver JA. Correlates among healthy lifestyle cognitive beliefs, healthy lifestyle choices, social support, and healthy behaviors in adolescents: implications for behavioral change strategies and future research. J Pediatr Health Care 2011;25:216-23.

68. Wang RH, Chen SW, Tang SM, Lee SL, Jian SY. The relationship between selected developmental assets and health-promoting behaviours of adolescents in Southern Taiwan. J Clin Nurs 2011;20:359-68.

69. Syvertsen AK, Wray-Lake L, Flanagan CA, Wayne Osgood D, Briddell L. Thirty-year trends in US adolescents' civic engagement: a story of changing participation and educational differences. J Res Adolesc 2011;21:586-94.

70. Carruthers C. Processes and outcomes of an after-school program for adolescent girls. J Park Recreat Admi 2006;24.

71. Purtell KM, McLoyd VC. Parents' participation in a work-based anti-poverty program can enhance their children's future orientation: understanding pathways of influence. J Youth Adolesc 2013;42:777-91.

72. Chaplin D, Capizzano J. Impacts of a summer learning program: a random assignment study of building educated leaders for life (BELL). Online Submission, 2006.

73. Ferrari A, Aricò M, Dini G, Rondelli R, Porta F. Upper age limits for accessing pediatric oncology centers in Italy: a barrier prevent- ing adolescents with cancer from entering national cooperative AIEOP trials. Pediatr Hematol Oncol 2012;29:55-61.

74. Springer JF, Wright LS, McCall GJ. Family interventions and adolescent resiliency: the Southwest Texas State high-risk youth program. J Community Psychol 1997;25:435-52.

75. Yu W. Educational experiment on primary school students' orientation and the longitudinal study. Tianjin Educ 10:13.

76. Sigal AB, Wolchik SA, Tein JY, Sandler IN. Enhancing youth outcomes following parental divorce: a longitudinal study of the effects of the new beginnings program on educational and occupational goals. J Clin Child Adolesc Psychol 2012;41:150-65.

77. Catalano RF, Fagan AA, Gavin LE, Greenberg MT, Irwin CE, Ross DA, et al. Worldwide application of prevention science in adolescent health. Lancet 2012;379:32-43.

78. Shek DT, Ma CM. Impact of the Project P.A.T.H.S. in the junior secondary school years: objective outcome evaluation based on eight waves of longitudinal data. ScientificWorldJ 2012. doi: $10.1100 / 2012 / 170345$.

79. Shek DT, Sun RC. Development and evaluation of positive adolescent training through holistic social programs (PATHS), Vol. 3. Singapore: Springer Science Business Media, 2013.

80. Ullrich-French S, McDonough MH, Smith AL. Social connection and psychological outcomes in a physical activity-based youth development setting. Res Q Exerc Sport 2012;83:431-41.

81. Ssewamala FM, Ismayilova L. Integrating children's savings accounts in the care and support of orphaned adolescents in rural Uganda. Soc Serv Rev 2009;83:453-72.

82. Jorgensen SR. Project taking charge: an evaluation of an adolescent pregnancy prevention program. Fam Relat 1991;40:373-80.

83. McNeal R, Handwerk ML, Field CE, Roberts MC, Soper S, Huefner JC, et al. Hope as an outcome variable among youths in a residential care setting. Am J Orthopsychiatry 2006;76:304-11.

84. Kirschman KJ, Roberts MC, Shadlow JO, Pelley TJ. An evaluation of hope following a summer camp for inner-city youth. Child Youth Care Forum 2010;39:385-96.

85. Pittman K, Irby M. Preventing problems or promoting development: competing priorities or inseparable goals. Takoma Park, MD: International Youth Foundation, 1996.

86. Lai HH. China's western development program: its rationale, implementation, and prospects. Mod China 2002;28:432-66.

87. Shea M, Ma PW, Yeh CJ, Lee SJ, Pituc ST. Exploratory studies on the effects of a career exploration group for urban Chinese immigrant youth. J Career Assess 2009;17:457-77.

88. De Villiers M, Van den Berg H. The implementation and evaluation of a resiliency programme for children. S Afr J Psychol 2012;42:93-102.

89. Huppert FA, Johnson DM. A controlled trial of mindfulness training in schools: the importance of practice for an impact on well-being. J Posit Psychol 2010;5:264-74.

90. Storch EA, Arnold EB, Lewin AB, Nadeau JM, Jones AM, De Nadai AS, et al. The effect of cognitive-behavioral therapy versus treatment as usual for anxiety in children with autism spectrum disorders: a randomized, controlled trial. J Am Acad Child Adolesc Psychiatry 2013;52:132-42.

91. Song Y. Study on the effect of coaching of secondary school students' academic aspirations on academic satisfaction. J Psychol Sci 2006;29:951-3. 
92. Yang X, Kong K. Study on the effect of the coaching of aspirations and attribution training on enhancing academic satisfaction. J Psychol Sci 2005;28:99-103.

93. Wu FK, Shek DT. A case study: investigate the implementation of P.A.T.H.S. in a single school by analyzing the role of policy, program, people, process and place. Int J Adolesc Med Health 2012;24:201-6.

94. Shea M, Pei-Wen WM, Yeh CJ. Development of a culturally specific career exploration group for urban Chinese immigrant youth. Career Dev Q 2007;56:62-73.

95. Chung RCY. Hong Kong's smart identity card: data privacy issues and implications for a post-September 11th America. Asia-Pacific Law Policy J 2003;4:519-68.

96. Chung RCY, Bemak F. Group counseling with Asians. In: DeLucia-Waack J, Kalodner C, Riva M, editors. Handbook of group counseling and psychotherapy, 2nd ed. Thousand Oaks, CA: Sage, 2014:231-41.

97. Hayman FM. Kids with confidence: a program for adolescents living in families affected by mental illness. Aust J Rural Health 2009;17:268-72.

98. Shek DT, Ma CM. Impact of the Project P.A.T.H.S. in the junior secondary school years: Individual growth curve analyses. ScientificWorldJournal 2011;11:253-66.

99. Metcalfe SA, Aitken M, Gaff CL. The importance of program evaluation: how can it be applied to diverse genetics education settings? J Genet Couns 2008;17:170-9.

100. Leong FT, Gim RH. Career assessment and intervention with Asian Americans. In: Leong FT, editor. Career development and vocational behavior of racial and ethnic minorities. Hillsdale, NJ: Lawrence Erlbaum, 1995:193-226. 